\title{
TEMA -2016: Patogénesis de la enfermedad por virus del dengue. Revisión de la literatura
}
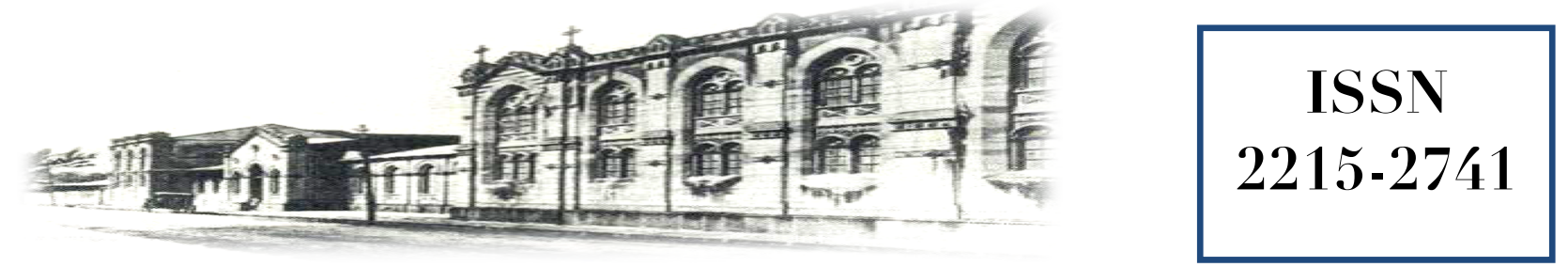

Haspital San quan de Dias, San Jasé, Costa Rica. Fundado en 1845

$\begin{array}{ll}\text { Recibido: } & 10 / 08 / 2014 \\ \text { Aceptado: } & 14 / 04 / 2016\end{array}$

\author{
Tutor $^{1}$ \\ Josué Beita Jiménez ${ }^{2}$ \\ Nazaret Salazar Arias ${ }^{3}$ \\ Michael Valverde Gómez ${ }^{4}$
}

${ }^{1}$ Grado Académico. Afiliación Institucional. Hospital San Juan de Dios. Correo electrónico.

${ }^{2}$ Médico General. Universidad de Costa Rica. Correo electrónico: josuebeita@hotmail.com

${ }^{3}$ Médico General. Universidad de Costa Rica. Correo electrónico: nazaret.sa@hotmail.com

${ }^{4}$ Médico General. Universidad de Costa Rica. Correo electrónico: julianjvg@hotmail.com

\section{RESUMEN}

El virus del dengue (DENV) pertenece a la Familia Flaviviridae, es transmitido por mosquitos del género Aedes; presenta una distribución mundial extensa, por lo que representa un problema de salud pública. Es un virus $\mathrm{ARN}$, con tropismos por múltiples células en el Humano, con un ciclo de reproducción bien establecido y estudiado. Ese ARN codifica para tres proteínas estructurales y siete no estructurales, con diferentes funciones e implicaciones patogénicas. Presenta 5 serotipos, 4 de importancia médica actual. Puede presentarse de manera asintomática $o$ sintomática. Este último se clasifica según la Organización Mundial de la Saludo (OMS) como Dengue y Dengue grave, el primero autolimitado y sin implicaciones severas, y el segundo con consecuencias clínicas que van desde fuga capilar leve, hasta formación de terceros espacios, fenómenos hemorrágicos, alteraciones gastrointestinales y neurológicas e inestabilidad hemodinámica. Se ha identificado una respuesta inmune a una primo infección que por lo general es menos severa que la segunda infección por un serotipo heterólogo. En este último escenario, se puede dar una respuesta intensificada anticuerpo dependiente (traducción del inglés antibodydependent enhancement), que aumenta la respuesta inflamatoria y tiene el potencial de causar un deterioro mayor, favoreciendo las presentaciones clínicas de Dengue severo.

\section{PALABRAS CLAVE}

Dengue. DENV. NS1. Patogénesis 


\section{ABSTRACT}

Dengue virus (DENV) belongs to the Flaviviridae family, it is transmitted by mosquitos of the Aedes genus, which has a worldwide distribution; this is the reason why it represents a public health issue. It is a RNA virus, with tropism for multiple human cells, with a well-established and studied viral cycle. The RNA encodes three structural and seven nonstructural proteins, each one of these with a different implication in the pathogenesis. DENV has five different serotypes, but only four are medically relevant. The disease can be asymptomatic or symptomatic. According to the World Health Organization (WHO), symptomatic disease is classified in Dengue and Severe Dengue, the first one has an auto limited presentation, and the second could have clinical consequences that range from mild capillary leak to third-space fluid shift, hemorrhagic phenomena, gastrointestinal and neurological alterations and hemodynamic instability. A primoinfection immune response has been elucidated, which usually is less severe than a second infection caused by a heterologous serotype, where an antibody-dependent enhancement amplifies the inflammatory response that could eventually cause a more severe clinical presentation.

\section{KEY WORDS}

Dengue. DENV. NS1. Pathogenesis

\section{INTRODUCCIÓN}

El Dengue es un Arbovirus de la Familia Flaviviridae, transmitido por dos vectores del género Aedes: A. aegypti, y A. albopictus. Actualmente representa un problema grave de salud pública de magnitud mundial, ya que es responsable de aproximadamente 50 a 100 millones de infecciones al año. ${ }^{1,2}$ En Costa Rica se reportó 1700 casos serológicamente confirmados en el año 2014, sin embargo se sabe que este dato subestima los casos reales debido a la gran prevalencia de infección asintomática ${ }^{3}$.

La enfermedad por el Virus del Dengue se clasifica según la OMS en Dengue y Dengue Grave (que incluye Dengue con signos de alarma, con Manifestaciones Hemorrágicas y Síndrome de Shock por Dengue). ${ }^{2} \mathrm{La}$ fiebre por
Dengue se caracteriza por artralgias, mialgias, cefalea, dolor retroocular, leucopenia y rash. Clásicamente conocida como "fiebre quiebrahuesos" y como "fiebre de los 7 días" tanto por el dolor generalizado y porque efectivamente suele autolimitarse por un periodo de aproximadamente una semana. El Dengue Grave a su vez presenta trombocitopenia, afección hepática, manifestaciones de fuga capilar, hemorragia, y en sus casos más severos inestabilidad hemodinámica y shock, todo esto en adición de los síntomas de la fiebre por Dengue convencional. ${ }^{1,2,4}$

Esta revisión tiene por objetivo ahondar en la patogénesis y fisiopatología de la enfermedad por el virus del Dengue en Humanos, con miras a una comprensión profunda de los mecanismos moleculares y celulares que influyen en el desarrollo y aparición de las diferentes manifestaciones clínicas.

\section{DISCUSIÓN}

\section{Estructura viral}

El virus del Dengue (DENV), se subdivide clásicamente en 4 serotipos bien descritos (DENV 1, 2, 3 y 4). Sin embargo desde octubre del 2013, se menciona en la literatura el serotipo 5 (DENV 5), sin relevancia epidemiológica por el momento. ${ }^{4,5,6}$ Presenta un genoma ARN de $11 \mathrm{~kb}$ que codifica diez proteínas que formarán el virus: 3 estructurales y 7 no estructurales. Las estructurales son la proteína de Cápside (C), Proteína de Membrana (M), y proteína de Envoltura (E). Las proteínas no estructurales (NS) son NS1, NS2A, NS2B, NS2B, NS3, NS4A, NS4B y NS5. ${ }^{4,6}$

\section{Proteínas estructurales}

El virus presenta una nucleocápside formada por la Proteína C, que cubre el genoma. Dicha estructura está rodeada por una bicapa lipídica donde se encuentran las proteínas $\mathrm{M}$ y $\mathrm{E}$. La proteína $\mathrm{M}$ se forma a partir de un precursor (prM), que participa en la regulación de la fusión viral y plegamiento de la proteína E. ${ }^{4,6} \mathrm{La}$ glicoproteína $\mathrm{E}$ de membrana tiene parte en la fusión de membrana, la morfogénesis del virión y unión al receptor. La Proteína E es la que 
establece el serotipo, con similitud de $60-70 \%$ en la secuencia de aminoácidos entre los cuatro DENV. ${ }^{4,6,7}$

\section{Proteínas no estructurales}

La glicoproteína NS1 presenta 3 categorías: Residentes del retículo endoplasmático, ancladas a membrana y la forma secretada (que puede estar en el espacio extracelular, con lo cual puede estimular el sistema inmune). En el suero de pacientes con DENV se ha demostrado la presencia de inmunoglobulinas contra esta proteína. Las Inmunoglobulinas contra la NS1 (in vitro) pueden provocar lisis mediada por complemento y dependiente de anticuerpos en células infectadas y no infectadas, lo que explica en parte el daño al endotelio, y sus consecuencias fisiopatológicas. ${ }^{4,6,7}$

NS2A es una proteína integral de membrana que participa en la replicación del ARN, por medio de un mecanismo aún no bien definido establece si el ARN va a servir como plantilla para la producción de componentes virales o si va a ser envuelto y formar parte de un nuevo virión ${ }^{4,6}$. NS2B es un cofactor de la proteasa NS3. La NS3 tiene relación con funciones de trifosfatasa de nucleósidos y helicasa durante la síntesis de ARN viral. NS4A es una proteína integral crítica para la formación de vesículas. NS4B es supresor de interferón gamma y beta. NS5 juega un papel importante en la síntesis de ARN y en el bloqueo de interferón, actúa como polimerasa en la transcripción y replicación viral. ${ }^{4,6}$

\section{Ciclo viral}

Tanto en las células de mamíferos como en las del mosquito vector el ciclo inicia con el acercamiento del DENV a la superficie de la célula. La proteína $\mathrm{E}$ interactúa con proteínas y proteoglucanos (como el heparán sulfato) de la membrana celular, con lo que se media la unión y endocitosis. Los proteoglucanos por su alta carga negativa favorecen el acercamiento de la partícula viral. ${ }^{4,6,7}$

Hay evidencia que sugiere que el receptor para laminina LAMR1 interactúa específicamente con la proteína $\mathrm{E}$, y que este es el que probablemente promueve la endocitosis. Se mencionan en la literatura otras proteínas que posiblemente actúen como receptores como la ICAM-3 y la DC-SIGN (Dendritic Cell Specific Intercellular Adhesion Molecule-3-Grabbing Non integrin, CD209) ${ }^{6}$. La vesícula endocítica pasa a ser endosoma temprano, tardío y posteriormente se fusiona con un lisosoma, que reduce el $\mathrm{pH}$, lo cual induce un cambio conformacional en la proteína $\mathrm{E}$ que favorece la liberación de la nucleocápside al citoplasma. ${ }^{4,6}$

El mecanismo mediante el cual se da la replicación del ARN viral aún no está esclarecido en su totalidad, sin embargo, se sabe que dicho nucleótido traduce un polipéptido completo, que es procesado a nivel del retículo endoplasmático por proteasas propias de la célula y por la NS3 ${ }^{6}$. Con la actividad de estas últimas se liberan las proteínas estructurales y no estructurales, las cuales son ensambladas en el mismo retículo. Posteriormente se da un proceso de maduración que involucra al aparato de Golgi. Cuando el virus es liberado por medio de exocitosis, la proteína $\mathrm{E}$ adquiere su conformación final favorecida por el $\mathrm{pH}$ neutro extracelular, con lo que puede ser reconocida por nuevas células y así iniciar nuevamente el ciclo viral. $^{4,6}$

\section{Patogénesis}

\section{Tropismo celular}

Las células a las cuales clásicamente se ha postulado que infecta el virus son: monocitos, macrófagos, células dendríticas, queratinocitos y linfocitos CD4+ y CD8+, sin embargo se ha demostrado que también puede hacerlo en: hepatocitos, endotelio, fibroblastos, neuronas y plaquetas, en esta última inclusive se ha demostrado que pueden llegar a completar su ciclo viral. ${ }^{4,6-9}$

Las células dendríticas y los queratinocitos son los sitios primarios de infección, ya que tienen contacto directo con la inoculación viral por parte del artrópodo ${ }^{4}$. De aquí el virus migra a los ganglios linfáticos, donde se amplifica y disemina la infección, con el eventual compromiso de todas las células mencionadas, una vez alcanzado el sistema circulatorio ${ }^{4,6,9}$. 


\section{Respuesta inmune en la primoinfección}

La glicoproteína $\mathrm{E}$ es la que presenta mayor exposición en el virus; se ha observado que la inmunidad contra el DENV es mediada principalmente por anticuerpos neutralizantes contra dicha proteína, aunque también en menor grado contra prM, C y las no estructurales ${ }^{7}$. La proteína NS1 ha cobrado relevancia en investigaciones recientes como factor altamente inmunogénico. ${ }^{8-11}$

Inicialmente, al establecerse la infección, existe una respuesta con secreción de interferones (IFN) de tipo I ( $\alpha$ y $\beta$ ), además de activación del sistema del complemento. 4, 12 De manera paralela por reconocimiento de las células presentadoras de antígenos y de las células infectadas, se produce un estímulo a los linfocitos Natural Killer, y se inicia la formación de una compleja cascada defensiva. La activación de estas células inmunes, y en especial de los linfocitos T CD8+, genera un estado antiviral y proinflamatorio, se da una producción y liberación aumentada de interleucinas, donde destacan: IL-1 $\beta$, IL-2, IL-4, IL-6, IL-7, IL-8, IL13, IL-18, TGF-1 $\beta$, TNF- $\alpha$ e IFN de tipo II $(\gamma){ }^{4}$, $7,9,12$

La respuesta inmune adaptativa ante una primo infección corresponde a la producción por parte de las células B de IgM contra los antígenos virales, y a continuación IgG, predominantemente IgG1 e IgG3. ${ }^{4,7,9}$ Los IgM se detectan hacia el quinto o sexto día por medio de ELISA, y pueden permanecer positivos de 2 a 3 meses, lo cual es una consideración importante a la hora de realizar un diagnóstico serológico. ${ }^{12}$

\section{Respuesta inmune en segunda infección}

En una segunda infección por DENV se observa una respuesta IgG acelerada en contraste a una IgM disminuida ${ }^{7}$. Se ha visto que en una primera infección por determinado serotipo se induce inmunidad homotípica prolongada, y además provee inmunidad transitoria contra serotipos heterólogos, lo cual se ha explicado en parte por la similitud conformacional de la glucoproteína $\mathrm{E}$ entre los DENV, como se describió anteriormente. Esto significa en términos generales que una segunda infección por el serotipo homólogo por lo tanto, es poco probable. $^{4,7,9,12}$

Una segunda infección por un serotipo heterólogo, en cambio, puede causar una respuesta intensificada anticuerpo dependiente (AED por sus siglas en inglés antibodydependent enhancement), lo cual a su vez traduce inflamación exacerbada, con consecuencias fisiopatológicas deletéreas. ${ }^{4,6,7,9}$ Se postula que esta AED se da porque a pesar de que en la primo infección hay producción de anticuerpos neutralizantes (capacidad que permanece en el tiempo gracias a las células B de memoria), cuando se da la infección por un serotipo heterólogo, los IgG secretados no logran neutralizar este virus de características molecularmente distintas. Estos anticuerpos en vez de producir una adecuada opsonización y supresión, se unen al virus heterólogo, posteriormente al macrófago o monocito a través del receptor Fc $\gamma$, que en vez de generar la eliminación del patógeno, favorece su endocitosis sin inactivarlo, con lo que potencia su capacidad de realizar su ciclo. ${ }^{4,7,9,12}$

La reacción inflamatoria exacerbada que se mencionó, tiene un componente de inmunidad celular. Se ha postulado que las células T CD8+ de memoria ante infección por serotipos homólogos a su primera exposición mantiene una respuesta adecuada. Sin embargo, con los serotipos heterólogos presenta secreción aumentada de interleucinas, que no es tan efectivo para la eliminación del virus y perpetúa el ciclo proinflamatorio. ${ }^{4,7,9}$

\section{Activación del complemento y autoanticuerpos}

El sistema del complemento confiere una primera línea de defensa contra los patógenos. $\mathrm{Su}$ activación está presente tanto en la primera como en las subsecuentes infecciones. ${ }^{9}$

En pacientes son síndrome de Shock por Dengue, durante el tiempo de defervescencia, cuando clínicamente empieza a ser evidente el escape capilar y la redistribución de líquidos, se ha demostrado niveles altos de productos de C3a y C5a en plasma, seguido de un consumo acelerado y una reducción marcada del complemento. Se han postulado diferentes 
mecanismos, uno de los más importantes la activación directa por la proteína no estructural 1. ${ }^{9,10,11}$ Se ha demostrado que la proteína NS1 tiene acción directa sobre el complemento, generando activación del complejo de ataque a membrana, tanto en su fase secretada como cuando es expresada por las células infectadas. ${ }^{4,}$ 10,11

Esta proteína no sólo tiene efectos a nivel del complemento. Se ha determinado que la reacción inmunológica que desencadena anticuerpos específicos anti NS1 puede resultar en ataque a elemento propios del huésped. ${ }^{8,9} \mathrm{El}$ endotelio y las plaquetas son los que se ven mayormente afectados por este proceso, ya que en su membrana expresan antígenos con similitudes estructurales a dicha proteína ${ }^{8}$. Una vez que se produce infección de estos elementos celulares, el ataque del sistema inmune se justifica también en reconocimiento de antígenos virales, por lo tanto la "autoinmunidad" no es el único proceso participando. ${ }^{7,8}$

\section{Aumento de permeabilidad capilar y extravasación}

La permeabilidad capilar característica de los cuadros clínicos severos por Dengue tiene un origen multifactorial. Existe evidencia que sugiere que hay una activación endotelial, con vacuolización y hendiduras en las uniones inter endoteliales, como consecuencia de la infección por DENV ${ }^{11,13}$. La afección del endotelio per se, juega un papel importante por la inmunidad citotóxica dirigida hacia las células infectadas, con consecuente apoptosis o necrosis que favorece la disrupción de la integridad capilar. ${ }^{4}$ $7,9,11$

El glucocálix tiene como función la selección restrictiva de moléculas, de acuerdo a su carga, tamaño y forma. ${ }^{1} \mathrm{La}$ tormenta de citoquinas genera modificación del glucocálix y de las uniones estrechas, con lo cual favorecen la hiper permeabilidad y la eventual fuga capilar. 1, 8, ${ }^{9}$ Además, durante el dengue puede observarse hipoalbuminemia y proteinuria, lo cual junto con el aumento de la permeabilidad del glucocalix favorece la extravasación de líquido ${ }^{1,9}$. Todos estos procesos juntos son los responsables de formación de terceros espacios (ascitis, derrame pleural), y edema (intestinal, pulmonar, cerebral), y consecuentemente de hipoperfusión tisular. $^{1,9,12}$

\section{Trombocitopenia y alteración de homeostasia} de la coagulación

La trombocitopenia es un fenómeno consistente tanto en episodios clínicos leves como severos. Se debe a dos mecanismos principalmente. El primero la supresión de la médula ósea (lo cual también explica parte de la leucopenia), y segundo el efecto autoinmune por reacción cruzada con los anticuerpos contra la proteína NS1. ${ }^{1,8,9}$

NS1 tiene la capacidad de unirse a la protrombina, disminuyendo su activación y provocando alteración de la hemostasia de la coagulación, además de que puede desencadenar transducción de señales en algunas células, con lo que aumentan la secreción de citoquinas y generan un mayor estado proinflamatorio. $8,9,11$

\section{Alteraciones gastrointestinales}

La noxa hepática se ha visto que tiene relación a procesos de apoptosis en hepatocitos inducida por DENV, más que a fenómenos de necrosis ${ }^{9}$. Esto genera un aumento de las transaminasas sin elevación importante de las bilirrubinas 9, 14, 15 . La ascitis que se presenta en los casos de Dengue severo y síndrome de Shock por Dengue se debe más a la extravasación por aumento de la permeabilidad capilar que a la hepatitis propiamente, ya que no suele ser tan severa. 1,9, ${ }^{12,}{ }^{15}$ De igual manera la coagulopatía tiene más relación con los fenómenos inflamatorios, la interacción de la protrombina con la NS1, que con la afección hepática. ${ }^{8,9,11}$

No sólo genera afección a nivel hepático, ya que las manifestaciones gastrointestinales están presentes en el $70 \%$ de pacientes con infección sintomática por Dengue. ${ }^{14,}{ }^{15}$ De ellas las más frecuentes son náuseas y vómitos, sin embargo se presentan otras como diarrea y dolor abdominal, y en casos más excepcionales, pancreatitis y colecistitis. ${ }^{1,14,15} \mathrm{Se}$ ha determinado que en adultos estos síntomas tienen relación con hemorragia en el tubo digestivo alto; en cambio en niños, las manifestaciones gastrointestinales tienen relación con la gravedad del cuadro, son 
más frecuentes en dengue hemorrágico y síndrome de shock por dengue. ${ }^{14,15}$

Sin embargo esta es una correlación epidemiológica, aún no se describe en la literatura ninguna teoría fisiopatológica. ${ }^{15}$

\section{Alteraciones neurológicas}

Las alteraciones neurológicas por el virus del dengue son raras, sólo presente en un $1 \%$ a $5 \%$ en algunas series ${ }^{16 .}$ A pesar de que desde 1976 ya se reportaban casos de alteraciones neurológicas con relación a infección por DENV, y que desde la década de 1990 se encontró evidencia indirecta como producción intratecal de inmunoglobulinas específicas contra el virus, fue hasta el 2007 que se demostró por ensayo biológico el neurotropismo del DENV como causante directo de leptomeningitis y encefalitis en ratones. ${ }^{16,17}$

Las hipótesis establecidas por la literatura involucran tres mecanismos patogénicos principales. 1. El neutrotropismo que se mencionó anteriormente, como responsable de la encefalitis, meningitis, miositis y mielitis ${ }^{18}$. Las complicaciones sistémicas resultantes en encefalopatía y parálisis hipokalémica, como hipotensión, edema cerebral, hemorragia microvascular o franca, hiponatremia y falla fulminante hepática. ${ }^{18,19}$ Además, se podría presentar un cuadro de encefalomielitis postinfecciosa con mediación inmune, que incluye también al síndrome de Guillain Barré y la neuritis óptica. ${ }^{18}$

\section{CONCLUSIONES}

El virus del Dengue tiene la capacidad de generar desde una infección asintomática hasta una infección con manifestaciones severas que pueden llevar inclusive a un estado de shock.

Por su gran incidencia mundial, ha sido ampliamente estudiado, con lo cual se han logrado dilucidar algunos de los mecanismos que involucran activación del sistema inmune innato y adaptativo, y su acción sobre eventos fisiopatológicos con traducción clínica como la trombocitopenia, la tendencia al sangrado, el aumento de la permeabilidad capilar, la afección gastrointestinal y neurológica.

El conocer estos eventos puede conferir al clínico la capacidad de enfrentarse a las desafiantes complicaciones que puede presentar un cuadro de dengue severo, y además puede ayudarle a establecer esta patología como un diagnóstico diferencial cuando el desarrollo de la enfermedad se aleja de la presentación usual.

\section{BIBLIOGRAFÍA}

1. Simmons C Farrar J van Vih Chau N. Dengue. N Engl J Med. 2012; 36: 1423-1432

2. OMS. Dengue y Dengue grave. Nota descriptiva $\mathrm{N}^{\circ}$ 117. 2015. Disponible en http://www.who.int/mediacentre/factsheets/f s117/es/

3. González M. Datos de análisis serológicos y serotipos circulantes de Dengue Costa Rica, enero-diciembre, 2014. INCIENSA. 2015: 1-10. Disponible en http://www.inciensa.sa.cr

4. Islam R Salahuddin M Salahuddin MA et al. Dengue epidemiology and pathogenesis: images of the future viewed through a mirror of the past. Virologica Sinica. 2015; 30 (5): 326-343

5. Mustafa MS Rasotgi V Jain S Gupta V. Discovery of fifth serotype of dengue virus (DENV-5): A new public health dilema in dengue control. Medical Journal Armed Forces India. 2015; 71: 67-70

6. Velandia ML Castellanos JE. Virus del Dengue: Estructura y Ciclo Viral. Infectio. 2011; 15 (1): 33-43

7. Murphy B Whitehead S. Immune Response to Dengue Virus and Prospects for a Vaccine. Annu Rev Immunol. 2011; 29: 587619

8. Simon A Sutherland M Pryzdial E. Dengue virus binding and replication by platelets. Blood. 2015; 126 (3): 378-385

9. Mortina B Koraka P Osterhaus A. Dengue Virus Pathogenesis: an Integrated view. Clinical Microbiology Reviews. 2009; 22 (4): 564-581

10. Kurosu $\mathrm{T}$ Chaichana Yamate $\mathrm{M}$ Anantapreecha S Ikuta K. Secreted comple- 
ment regulatory rotein clusterin interacts with dengue virus non structural protein 1. Biochem Biophys Res Commun. 2007; 362: 1051-1056

11. Chuang Y Wang S Lin Y Chen H Yeh T. Re-evaluation of the pathogenic roles of nonstructural protein 1 and its antibodies during dengue virus infection. Journal of Biomedical Science. 2013; 20: 42

12. Montes de Oca M Martín P Monsalvo M Ruiz E. Infecciones víricas endémicas: dengue, fiebre del Nilo, otras. Medicine. 2014; 11 (50): 2965-2972

13. Sosothikul D Seksarn P Pongsewalak S Thisyakorn U Lusher J. Activation of endothelial cells, coagulation and fibrinolysis in children with Dengue virus infection. Thromb Haemostasis 2007, 97:627-634.

14. Ooi E Ganesananthan S Anil R Kwok FY Sinniah M. Gastrointestinal Manifestations of Dengue Infection in Adults. Med J Malaysia. 2008; 63 (5): 401-405

15. Ramos A Remes J González $M$ et al. Sintomas abdominales y gastrointestinales del dengue. Análisis de una cohorte de 8.559 pacientes. Gatroenterol Hepatol. 2011; 34 (4): $245-247$

16. Puccioni-Sohler M, Rosadas C, CabralCastro MJ. Neurological complications in dengue infection: a review for clinical practice. Arq Neuropsiquiatr 2013;71:667-671.

17. Bordignon J Strottmann D Mosimann A et al. Dengue neurovirulence in mice: identification of molecular signatures in the $E$ and NS3 helicase domains. J Med Virol 2007;79:1506-1517.

18. Verma R, Sharma P, Garg RK, Atam V, Singh MK, Mehrotra HS. Neurological complications of dengue fever: Experience from a tertiary center of north India. Annals of Indian Academy of Neurology. 2011;14(4):272-278.

19. Solomon T Minh N Vaughn D Kneen R et al. Neurological manifestations of dengue infection. The Lancet. 2000; 335: 1054-1059

\section{CONFLICTO DE INTERÉS Y/O AGRADE- CIMIENTOS}

Los autores declaran que no existió ningún conflicto de interés en el presente reporte. 